\title{
EVIDENCIAÇÃO DE INSTRUMENTOS FINANCEIROS DERIVATIVOS NAS DEMONSTRAÇÕES CONTÁBEIS: UMA ANÁLISE DAS EMPRESAS BRASILEIRAS*
}

\author{
LEANDRO LUÍS DARÓS \\ Bacharel em Administração e Ciências Contábeis pela UFSC - SC \\ Mestrando do Programa de Pós-Graduação em Contabilidade da UFSC - SC \\ E-mail: Idaros@hotmail.com

\section{JOSÉ ALONSO BORBA} \\ Prof. Dr. do Depto. de Ciências Contábeis e do \\ Programa de Pós-Graduação em Contabilidade da UFSC - SC \\ E-mail: jalonso@cse.ufsc.br
}

\section{RESUMO}

Dentro da perspectiva de governança corporativa e de acordo com a Instrução Normativa 235 da Comissão de Valores Mobiliários - CVM, este trabalho apresenta uma pesquisa empírica sobre as formas de evidenciação de instrumentos financeiros derivativos nas Demonstrações Contábeis divulgadas no Brasil. Foram analisadas as Demonstrações Contábeis das vinte maiores empresas brasileiras não financeiras classificadas de acordo com a receita líquida. Como resultado constatou-se que a grande maioria das empresas não atende às determinações da CVM e não evidencia, de forma clara, concisa e objetiva, as informações referentes às suas operações envolvendo instrumentos financeiros derivativos. As principais divergências estão na falta de avaliação dos instrumentos a preços de mercado, ausência de divulgação das políticas de investimento em derivativos e falta de controle do risco de mercado, câmbio e crédito.

Palavras-chave: Demonstrações Financeiras; Derivativos; Evidenciação.

\begin{abstract}
In the context of financial statement disclosure and in accordance with determinations by the Brazilian Securities and Exchange Commission, this study presents rules and ways to disclose derivatives in financial statements. In the empirical analysis, we examined the financial statements of the twenty biggest public companies arranged by revenue. We verified that many companies do not comply with the Brazilian Securities and Exchange Commission's determinations and do not present a clear, concise and objective disclosure of related financial information. The main problems were related to the lack of evaluation in terms of fair value, lack of dissemination of investment policies in derivatives and quantitative and qualitative control of market, credit and exchange risks.
\end{abstract}

Keywords: Financial Statements; Derivatives; Disclosure.

Recebido em 12 Abr. 2005 • Aceito em 23 Jun. 2005

* Artigo originalmente apresentado no XXVIII ENANPAD, setembro de 2004, Curitiba-PR. 


\section{INTRODUÇÃO}

Demonstrar as alterações patrimoniais e gerar informações é um dos objetivos da Contabilidade. Essa tarefa tem se tornado cada vez mais complexa nos últimos anos devido, principalmente, ao desenvolvimento e volatilidade do sistema financeiro e pela sofisticação e complexidade das transações econômicas. Dentro desse contexto, um tipo especial de operação financeira, os instrumentos financeiros derivativos, se desenvolveram com grande rapidez e criaram dificuldades de seu reconhecimento e mensuração por parte da Contabilidade. Criados com a finalidade de antecipar preços futuros de seus ativos objeto e proteger investidores e produtores contra riscos, os derivativos são, hoje, papéis largamente comercializados no mercado financeiro internacional. Contratos futuros, a termo, opções e swaps são exemplos desses contratos derivativos. A complexidade de muitos deles, que por vezes são estruturados sobre sofisticados sistemas de cálculos, tem despertado a atenção da contabilidade para entender e reconhecer seus efeitos sobre a situação patrimonial das empresas e, concomitantemente, identificar a maneira correta de evidenciá-los nas Demonstrações Contábeis.

De acordo com Benston e Mian (1997), o tamanho, crescimento e importância do mercado de derivativos indicam um amplo uso desses instrumentos financeiros pelas empresas. Contudo, apesar do seu uso intensivo, os contadores têm carência de orientações para a sua evidenciação, reconhecimento, mensuração e classificação. Em decorrência disso, a profissão contábil tem enfrentado dificuldades na formulação de métodos claros e compreensíveis a respeito do reconhecimento e apresentação desses instrumentos.

Um dos aspectos que tem prejudicado o trabalho de demonstrar o impacto dos derivativos nas empresas é o fato de publicações e instruções de contabilização de operações com instrumentos financeiros derivativos serem bastante recente em nosso país.

Apesar da CVM exigir desde 1995 a evidenciação em notas explicativas desse tipo de operação, havia uma lacuna no meio contábil sobre como contabilizar e reconhecer operações com derivativos. Uma grande contribuição para a solução desse problema foram as emissões, em 1998, do SFAS ${ }^{1}$ 133 pelo FASB - Financial Accounting Standards
Board, em 1999, o IAS $39^{2}$ pelo IASB - International Accounting Standards Board e os estudos, no Brasil, realizados especialmente pelos pesquisadores Alexsandro Broedel Lopes, Luiz Nelson Carvalho e Jorge Vieira da Costa Junior. Ainda, assim, no exterior, diversas outras pesquisas têm discutido questões relacionadas com a divulgação, transparência e o impacto dos derivativos tanto nas Demonstrações Contábeis quanto nos seus usuários, como, por exemplo, os trabalhos de Guay (1999), Blankley, Lamb, Schroeder (2000), Seow e Tam (2002), Ishikawa (2003).

Assim, com base nas recomendações e modelos de contabilização da Instrução Normativa 235 da CVM, o presente trabalho busca analisar como as operações com instrumentos financeiros derivativos vêm sendo evidenciadas nas Demonstrações Contábeis de empresas brasileiras não financeiras.

A relevância deste trabalho concentra-se em analisar de que forma as empresas brasileiras não financeiras evidenciam operações com instrumentos financeiros derivativos em suas Demonstrações Contábeis já que transações desse tipo não fazem parte de seu contexto operacional. Por que adquirem contratos dessa natureza, como contabilizam e comunicam perdas e ganhos com esses contratos são questões discutidas no decorrer do presente trabalho.

Ainda assim, um trabalho desta natureza se torna necessário pelas razões apresentadas a seguir:

- deve-se considerar a elevada importância dos instrumentos financeiros derivativos no contexto do mercado financeiro internacional. As transações com esses produtos alcançam alguns trilhões de dólares e eles são peças importantes numa estratégia de gestão de risco realmente eficaz no âmbito internacional ${ }^{3}$;

- o mercado financeiro internacional vem enfrentando modificações significativas nos últimos anos causadas pela quebra de barreiras ao fluxo de capitais e desregulamentações nacionais. Dentro desse contexto, a gestão do risco passou a ser um ponto crítico na estratégia da maioria das instituições financeiras internacionais e os derivativos se tornaram instrumentos fundamentais nesse novo modelo de gestão;

\footnotetext{
${ }^{1}$ Statement of Financial Accounting Standars - SFAS 133 - Accounting for derivatives instruments and hedging activies - Junho/1998.

${ }^{2}$ IAS - International Accounting Standard - IAS 39 - Financial instruments: recognition and measurement.

${ }^{3}$ GAO: General Accounting Office, Special Report to US Congress on Financial Instruments and Capital Markets, 1998. p. 18.
} 
- os efeitos dos derivativos não são transparentes nas Demonstrações Financeiras básicas. Com a inexistência de uma abordagem completa para a contabilização desses produtos, há uma inconsistência geral no modelo de evidenciação e contabilização de cada entidade considerada internacionalmente ${ }^{4}$;

- a crescente utilização de instrumentos financeiros derivativos no mercado internacional com operações de hedge, especulação e arbitragem associada às crises de instituições respeitadas como, por exemplo, o Banco inglês Barings, trouxeram esses produtos para o centro da atenção de instituições financeiras e órgãos reguladores;

- a precificação de instrumentos financeiros derivativos exige um instrumental quantitativo extremamente avançado que parece fugir ao domínio da maioria dos profissionais do mercado financeiro e dos contadores em particular. Dessa forma, a dificuldade no entendimento dos mecanismos de formação de preço dos derivativos leva a equívocos de interpretação por parte da Contabilidade;

- Ishikawa (2003) pontua que a introdução do "valor justo" na contabilidade para avaliar instrumentos financeiros derivativos está profundamente relacionada com a necessidade de evidenciar as diversas características qualitativas e quantitativas desses ativos, fundamentalmente, em decorrência da sofisticação, diversificação e expansão desses mercados e a conseqüente proliferação de seu uso.

\section{METODOLOGIA}

Para a consecução dos objetivos foi realizado um estudo exploratório descritivo que segundo Lakatos e Marconi (1992) "é toda pesquisa que busca constatar algo num organismo ou num fenômeno". Como esse trabalho analisa as formas de evidenciação de derivativos nas Demonstrações Contábeis esse tipo de estudo é o mais adequado para se atingirem os objetivos da pesquisa.

A população definida para análise na pesquisa são as empresas brasileiras, Sociedades Anônimas de Capital Aberto, não Financeiras. Justifica-se a escolha dessas empresas pelos critérios abaixo elencados:
1. Empresas brasileiras: busca-se analisar as empresas de um determinado espaço geográfico e que respeitem a uma mesma legislação. Não faria sentido, por exemplo, analisar empresas de diferentes países com legislações diferentes, o que, sem dúvida, prejudicaria a uniformidade das informações. Assim, as empresas brasileiras foram escolhidas pelo fato de o trabalho estar sendo realizado no Brasil e pela conveniência de obtenção de informações relativas a essas empresas.

2. Empresas Sociedade Anônima de Capital Aberto: a fonte de coleta de dados são as demonstrações contábeis das empresas. 0 artigo 176 da Lei 6.404 de 1976, que trata das Sociedades Anônimas, diz que: "Ao fim de cada exercício social, a diretoria fará elaborar, com base na escrituração mercantil da companhia, as seguintes demonstrações financeiras, que deverão exprimir com clareza a situação do patrimônio da companhia e as mutações ocorridas no exercício:

I balanço patrimonial;

II demonstração dos lucros ou prejuízos acumulados;

III demonstração do resultado do exercício; e IV demonstração das origens e aplicações de recursos."

Assim, todas as empresas sociedades anônimas são obrigadas a publicar as Demonstrações Contábeis, de onde são coletados os dados. No que diz respeito às empresas de capital aberto, justifica-se sua utilização por essas empresas possuírem papéis negociados em Bolsa, ou seja, são empresas que devem apresentar informações aos acionistas de seus negócios, mais especificamente, nesse caso, sobre derivativos;

3. Empresas não financeiras: optou-se por analisar as empresas não financeiras, pois realizar operações com derivativos não faz parte de seu contexto operacional. Assim, busca-se analisar por que empresas não financeiras utilizam derivativos e como os evidenciam nas Demonstrações Contábeis;

4. Por fim, entenda-se como empresa brasileira de capital aberto aquelas registradas como Sociedades Anônimas de Capital Aberto na Comissão de Valores Mobiliários e na Bolsa de Valores de São Paulo e com ações negociadas no mercado.

${ }^{4}$ LOPES, A. B.; CARVALHO, L. N. G.. Contabilização de operações com derivativos: uma comparação entre o SFAS 133 e o arcabouço emanado pelo COSIF. Caderno de Estudos, São Paulo, FIPECAFI, n. 20, jan/abr., 1999, p. 22. 
Definida a população, para a seleção da amostra de pesquisa foi utilizado o software de informações financeiras e econômicas Economática ${ }^{\mathrm{TM}}$. De acordo com a definição da amostra e os recursos do programa, foram estabelecidos os parâmetros apresentados no Quadro 1:

Através desse método, foram selecionadas 195 empresas, ordenadas em ordem decrescente em função da receita líquida constante na Demonstração do Resultado do Exercício do ano de 2002. Para estabelecer-se o tamanho da amostra, considerou-se a representatividade da amostra em relação a população em função da receita líquida anual constante na Demonstração de Resultado de Exercício de 31 de dezembro de 2002.

\begin{tabular}{|llll|}
\hline PARÂMETRO & LIMITADOR & RESTRIÇÃo & DEFINIÇÃo \\
\hline País & Igual a & Brasil & Empresas registradas em Bolsas brasileiras \\
\hline Bolsa & Igual a & BRA-Bovespa & $\begin{array}{l}\text { Empresas cujo os papéis são negociados } \\
\text { na Bovespa }\end{array}$ \\
\hline Tipo de ativo & Igual a & Ação & Tipo de ativo \\
\hline Setor Econômico & Diferente de & Finanças e Seguros// & $\begin{array}{l}\text { Empresas que não pertencem } \\
\text { a nenhum desses três setores }\end{array}$ \\
\hline Ativo/Cancelado & Igual a & Ativo & Papéis que são válidos para negociação \\
\hline Receita líquida do último balanço & Maior que & $\mathrm{R} \$ 0,00$ & Receita auferida no último balanço \\
\hline
\end{tabular}

Fonte: Elaborado pelos autores com base em informações do Economática.

\section{Quadro 1 - Critérios de Seleção da Amostra}

Assim, trabalhou-se com uma representatividade de $67,2758 \%$ o que representa um número de 20 empresas do total de 195 empresas da população. Isso significa que 20 empresas tomadas como amostra representam $67,2758 \%$ da receita liquida total da população. A despeito da amostra ser não probabilística, optou-se por trabalhar-se com essas empresas pois são as vinte maiores empresas brasileiras não financeiras com a receita líquida bastante concentrada. Contudo, enfatiza-se, os resultados não podem (estatisticamente) ser generalizados para toda população. As empresas selecionadas como amostragem estão relacionadas no Quadro 2 a seguir:

\begin{tabular}{|lll|}
\hline ORDEM & EMPRESA & SETOR \\
\hline 1 & PETROBRAS & Petróleo e Gás \\
\hline 2 & TELESP & Telecomunicações \\
\hline 3 & $\begin{array}{l}\text { COMPANHIA VALE } \\
\text { DO RIO DOCE }\end{array}$ & Mineração \\
\hline 4 & EMBRAER & Veículos e peças \\
\hline 5 & BRASIL TELECOM & Telecomunicações \\
\hline 6 & ELETROPAULO & Energia Elétrica \\
\hline 7 & CEMIG & Energia Elétrica \\
\hline
\end{tabular}

Continuação

\begin{tabular}{|lll|}
\hline ORDEM & EMPRESA & SETOR \\
\hline 8 & $\begin{array}{l}\text { COMPANHIA } \\
\text { SIDERÚRGICA } \\
\text { NACIONAL }\end{array}$ & Siderurgia e Metalurgia \\
\hline 9 & VARIG & Transporte Serviços \\
\hline 10 & USIMINAS & Siderurgiae Metalurgia \\
\hline 11 & LIGHT & Energia Elétrica \\
\hline 12 & IPIRANGA PETRÓLEO & Petróleo e Gás \\
\hline 13 & TELEMAR & Telecomunicações \\
\hline 14 & ELETROBRÁS & Energia Elétrica \\
\hline 15 & COSIPA & Siderurgia e Metalurgia \\
\hline 16 & COMPANHIA & Siderurgia e Metalurgia \\
\hline 17 & SIDERÚRGICA & \\
\hline 18 & TUBARÃO & Comércio \\
\hline 19 & GLOBEX AÇÚCAR & Comércio \\
\hline 20 & CESP & Química \\
\hline
\end{tabular}

Fonte: Elaborado pelos autores com base em informações do Economática 
Selecionada a amostra, os dados das empresas foram coletados nas Demonstrações Contábeis encerradas em 31 de dezembro de 2002. Por Demonstrações Contábeis entendam-se os seguintes documentos: Balanço Patrimonial, Demonstração do Resultado do Exercício, Demonstração dos Lucros ou Prejuízos Acumulados ou Demonstração de Mutações do Patrimônio Líquido, Demonstração das Origens e Aplicação dos Recursos, acompanhadas de Notas Explicativas e o Parecer dos Auditores Independentes.

Salienta-se que na pesquisa utilizou-se apenas dados primários coletados diretamente das demonstrações contábeis das empresas. Essas demonstrações foram obtidas através do sistema de informações da CVM disponibilizado na Internet através das Demonstrações Financeiras Padronizadas do ano de 2002.

Com base nas informações sobre a legislação e nos modelos de evidenciação de derivativos constantes em instruções da CVM foram estabelecidos itens que deveriam constar nas demonstrações contábeis das empresas. O primeiro item trata da presença ou não da nota explicativa sobre instrumentos financeiros derivativos. A seguir, analisou-se a política de divulgação dos objetivos, finalidades e intenções da empresa com o uso de derivativos, as premissas utilizadas para determinação dos valores justos e o uso de quadro comparativos mostrando as diferenças entre o valor contábil e o de mercado dos derivativos. Logo após, foram estabelecidos itens de análise do controle de risco que a empresa efetua sobre três aspectos: risco de crédito, risco de taxa de câmbio e risco de produto.

Os dados foram analisados individualmente de empresa para empresa e, em seguida, comparados entre si. Foram feitas análises quantitativas e qualitativas dos dados. Na análise quantitativa buscou-se verificar quantas empresas enquadravam-se dentro dos termos da legislação. Já na análise qualitativa foram comparadas as demonstrações das empresas, suas diferenças e similaridades e também o conteúdo das informações apresentadas.

\section{NORMAS CONTÁBEIS QUE TRATAM DE EVIDENCIAÇÃO DE DERIVATIVOS}

No Brasil, a principal norma que dispõe sobre a evidenciação nas Demonstrações Contábeis de Companhias Abertas do valor de mercado dos ins- trumentos financeiros é a Instrução Normativa 235 da CVM publicada em 23 de março de $1995^{5}$.

Segundo essa norma, as companhias abertas que possuam instrumentos financeiros, reconhecidos ou não como ativo ou passivo em seu balanço patrimonial, devem evidenciar, em nota explicativa, anexa às suas Demonstrações Financeiras e às informações trimestrais - ITR, o valor de mercado desses instrumentos financeiros. Devem demonstrar, ainda, em nota explicativa, os critérios e as premissas adotados para determinação desse valor de mercado, bem como as políticas de atuação e controle das operações nos mercados derivativos e os riscos envolvidos.

A norma define como instrumento financeiro "todo contrato que dá origem a um ativo financeiro em uma entidade e a um passivo financeiro ou título representativo do patrimônio em outra entidade". Pela instrução normativa são considerados como ativos financeiros:

a) disponibilidades;

b) direitos contratuais recebíveis em moeda ou em instrumentos financeiros de outra entidade;

c) direitos contratuais de troca de resultados financeiros (swaps) ou instrumentos financeiros;

d) títulos representativos de participação no patrimônio de outra entidade.

São caracterizados como passivos financeiros as obrigações contratuais de:

a) pagamento de determinada importância em moeda ou em instrumentos financeiros e

b) troca de resultados financeiros ou instrumentos financeiros.

A norma considera como deve ser avaliado o valor de mercado do instrumento derivativo:

I o valor que se pode obter com a negociação do instrumento financeiro em um mercado ativo, em que comprador e vendedor possuam conhecimento do assunto e independência entre si, sem que corresponda a uma transação compulsória ou decorrente de um processo de liquidação, ou

II na ausência de um mercado ativo para um determinado instrumento financeiro:

\footnotetext{
${ }^{5}$ As instituições financeiras e assemelhadas devem respeitar as normas determinadas pelo COSIF - plano contábil das instituições financeiras do sistema financeiro nacional do Banco Central do Brasil. Como o objeto de estudo deste trabalho são as empresas não financeiras, serão analisadas as determinações da CVM que é quem regula as Sociedades Anônimas não Financeiras.
} 
a) o valor que se pode obter com a negociação de outro instrumento financeiro de natureza, prazo e risco similares, em um mercado ativo, conforme referido no inciso I deste artigo ou

b) o valor presente líquido dos fluxos de caixa futuros a serem obtidos, ajustado com base na taxa de juros vigente no mercado, na data do balanço, para instrumentos financeiros de natureza, prazo e risco similares.

A companhia aberta deverá evidenciar, sempre que relevante:

a) o valor de mercado de todos os instrumentos financeiros, reconhecidos ou não como ativo/passivo em seu balanço patrimonial;

b) os critérios e premissas adotados para determinação desse valor e

c) as políticas de atuação e de controle das operações nos mercados derivativos e dos riscos envolvidos.

O artigo 4을 da Instrução CVM no 235/95 dispensa a divulgação dos valores de mercado de duplicatas a receber e a pagar. A CVM entende, também, ser desnecessária a divulgação dos valores de mercado das demais contas a receber e a pagar com prazo compatível com as operações normais da companhia. Essa dispensa está baseada no fato de as contas a receber e a pagar, bem como os demais itens monetários, serem ajustados a valor presente conforme requerido pela Instrução CVM no 191/92.

A dispensa acima, contudo, não se aplica a contas a receber de entidades governamentais ou outras decorrentes de contratos de longo prazo, cuja possibilidade de recebimento no prazo de até três meses não esteja efetivamente assegurada. Nesse caso, deverá ser informado, em nota explicativa, o valor de mercado ou, na ausência dessa informação, deverá ser indicada uma estimativa de desconto em função do custo de seu financiamento, de acordo com o prazo previsto para o seu recebimento.

A CVM estabeleceu para as instituições financeiras e não financeiras modelos de nota explicativa. O modelo proposto não esgota todas as necessidades de divulgação ou, ainda, de sua própria identificação e, portanto, deverá ser adaptado e analisado, criteriosamente, pela administração da companhia e seus auditores independentes.

As informações contidas nesses modelos de nota explicativa podem ser reunidas em uma única nota às Demonstrações Contábeis/informações trimestrais ou divididas em duas ou mais notas explicativas.

\section{ANÁLISE DE COMO AS EMPRESAS BRASILEIRAS EVIDENCIAM DERIVATIVOS EM SUAS DEMONSTRAÇÕES CONTÁBEIS}

Foi demonstrada no capítulo anterior, a norma que dispõe sobre a evidenciação de instrumentos financeiros derivativos nas Demonstrações Contábeis. Segue-se, agora, a análise empírica de como essas informações vêm sendo demonstradas ao mercado através de uma amostra das vinte maiores empresas brasileiras com atividade fim não financeira.

De acordo com a Instrução Normativa 235/95 da CVM, são analisados aspectos de divulgação dos objetivos, finalidades e intenções da empresa com o uso de derivativos, premissas utilizadas para determinação dos valores justos dos derivativos e controle de risco que a empresa efetua sobre três aspectos: risco de crédito, risco de taxa de câmbio e risco de produto.

Dado o grau de internacionalização, porte das empresas e universalização do uso de derivativos, foi adotado o pressuposto de que todas as empresas analisadas utilizam derivativos.

\subsection{Presença da Nota Explicativa sobre Instrumentos Financeiros Derivativos}

Inicialmente, buscou-se identificar nas Demonstrações Contábeis das empresas a presença da nota explicativa que trata de instrumentos financeiros derivativos, conforme determina a instrução CVM 235/95.

Pela verificação das demonstrações, constatou-se que das vinte empresas analisadas todas possuem notas explicativas sobre instrumentos financeiros.

Assim, as empresas atendem à legislação brasileira que determina a presença dessa nota nas Demonstrações. A análise desse tópico é mais quantitativa do que qualitativa já que a qualidade das informações, constantes nas notas explicativas, foram analisadas nos itens seguintes.

\subsection{Divulgação dos Objetivos, Fins e Intenções com o Uso de Derivativos}

A seguir, analisou-se nas Demonstrações Contábeis a presença dos objetivos, fins e intenções da empresa com o uso de instrumentos financeiros derivativos. Com esse item buscou-se identificar quais os motivos para as empresas utilizarem esse tipo de instrumento no decorrer de suas atividades e sua comunicação ao mercado. 
Como resultado verificou-se que 12 (60\%) das empresas analisadas divulgam essa informação ao mercado. A Cosipa, uma das empresas que evidenciou seus objetivos com derivativos nas Demonstrações Contábeis, apresentou o seguinte parágrafo na nota explicativa referente a instrumentos financeiros:

A companhia possui operações envolvendo instrumentos financeiros exclusivamente em conexão com suas atividades e com o objetivo de reduzir a exposição aos riscos de mercado, de moeda e taxas de juros, de seus ativos operacionais.

Já a Embraer expôs a seguinte justificativa para o uso de derivativos em suas operações:

Os instrumentos derivativos contratados pela Empresa têm o propósito de proteger as operações da empresa contra riscos de variação cambial e de flutuação na taxa de juros e não são utilizados para fins especulativos.

Assim, apesar de 8 (40\%) das empresas não fazerem qualquer referência, em suas notas explicativas, sobre suas intenções com instrumentos derivativos, as que as apresentam o fazem de forma clara. Saliente-se que essa informação é importante para o investidor verificar se a empresa especula no mercado financeiro utilizando derivativos ou se utiliza esses instrumentos como meio de proteção contra riscos decorrentes de suas atividades.

\subsection{Premissas de Avaliação}

As premissas de avaliação mostram como a empresa mensura o valor dos derivativos divulgados nas Demonstrações Contábeis. De acordo com a Instrução da CVM 235/95, as empresas devem ajustá-los a valor de mercado e divulgar as premissas utilizadas nesse processo de avaliação.

Das empresas analisadas, 5 (25\%) divulgaram essa informação, no entanto, de maneira vaga ou incompleta deixando dúvidas se a avaliação foi de fato realizada. As notas sobre esse tema, curiosamente, apresentam um padrão e são semelhantes à apresentada abaixo por uma das empresas:

Os valores justos dos ativos e passivos financeiros da Companhia foram determinados através de informações disponíveis no mercado e de aplicação de metodologias apropriadas de avaliações. Entretanto, considerável julgamento foi requerido na interpretação dos dados de mercado para se produzir a mais adequada estimativa do valor justo. Como conseqüência, as estimativas apresentadas a seguir não indicam, necessariamente, os montantes que poderão ser realizados no mercado de troca corrente. $\mathrm{O}$ uso de diferentes hipóteses e/ou metodologias de mercado pode ter um efeito material nos valores estimados de realização.

A nota evidencia uma informação de pouca relevância e não diz como realmente a avaliação foi feita. A empresa fala em "aplicação de metodologias apropriadas de avaliações" porém, que metodologias são essas? Com base em que elas foram realizadas? Ainda assim, a nota diz que "as estimativas apresentadas a seguir não indicam, necessariamente, os montantes que poderão ser realizados no mercado de troca corrente". Ora, a instrução da CVM é clara quando exige que os instrumentos derivativos sejam evidenciados a valores de mercado. Se a própria nota apresenta ressalva afirmando que os valores não são os de realização, fica evidente a falta de informação.

Saliente-se que apenas 5 (25\%) das empresas possuem informações sobre premissas de avaliação e a grande maioria delas com informações de baixa qualidade e padronizadas como a apresentada acima.

\subsection{Quadros Demonstrativos}

Os quadros demonstrativos servem como comparação dos valores contábeis registrados pelas empresas com as avaliações dos valores de mercado. Essa comparação presta-se a verificar as perdas ou ganhos da empresa com os derivativos. Nesse item, 9 (45\%) das empresas apresentam quadros comparativos. Aqui, surge uma questão interessante: se apenas 5 (25\%) das empresas avaliam seus investimentos em derivativos a preços de mercado como 9 (45\%) delas apresentam quadros comparativos? É uma boa pergunta e deixa dúvida se os valores constantes nos quadros comparativos são de fato fidedignos.

A Telesp, por exemplo, apresenta o seguinte quadro comparativo de suas operações envolvendo taxas cambiais.

A exposição líquida (excesso) pelo valor contábil e de mercado da Sociedade ao risco de taxa de câmbio em 31 de dezembro de 2002 e 2001, é demonstrada na tabela a seguir: 
Tabela 1 - Exposição Líquida

\begin{tabular}{lccccc} 
& \multicolumn{2}{c}{2002} & & \multicolumn{2}{c}{2001} \\
\cline { 2 - 3 } CONSOLIDADO & Posição cambial & Valor de Mercado & & Posição cambial & Valor de Mercado \\
Empréstimos e financiamentos & 4.169 .662 & 3.318 .458 & & 4.004 .032 & 4.090 .102 \\
\hline Fornecedores & 74.857 & 74.857 & - & 3.077 .006 \\
\hline Posição ativa em "swap" cambial & 4.244 .132 & 3.790 .553 & 2.974 .226 & (i) \\
\hline Posição ativa em opções cambiais & - & & 1.027 .937 & $\mathbf{1 . 8 6 9}$ \\
\hline Exposição líquida & $\mathbf{3 8 7}$ & & &
\end{tabular}

(i) Em 31 de dezembro de 2001 a Sociedade tinha US\$ 443.300 de valor nominal em diversas estruturas de opções cambiais, tais como "call', "call spread" e "operação gaivota". Naquela data, o valor de mercado das operações de opções apresenta um ativo de R $\$ 23.600$ caso a empresa resolvesse desfazerse das mesmas enquanto que o valor contábil ativo considerado para tais operações é de $\mathrm{R} \$ 32.600$. Na avaliação das opções a valor de mercado utilizouse o modelo "Black \& Scholes".

Fonte: Demonstrações Contábeis do ano de 2002 da Telesp.

A tabela 1, divulgada pela Telesp, apesar de sucinta, é bastante explicativa e apresenta a posição da empresa em relação a taxas cambiais, inclusive com o modelo de avaliação utilizado (Black \& Scholes) e a exposição líquida.

Outra empresa que também divulgou quadros comparativos com explicações foi a Companhia Siderúrgica Tubarão - CST, que está reproduzido na Tabela 2 abaixo.

O valor de mercado dos financiamentos foi determinado com base no valor presente do fluxo de caixa futuro, ajustado pela taxa de juros vigente no mercado para instrumentos financeiros de natureza, prazo e risco similares.

Em novembro de 2002, a Companhia efetuou operação com instrumento derivativo na modalidade "Swap" de CDB para dólar norte-americano. Em 31 de dezembro, a operação correspondia a $R \$ 18.087$, equivalentes a US\$ 5.119 mil e gerou um ganho de cerca de $\mathrm{R} \$ 177$, líquido de impostos.

Dessa forma, apesar de poucas empresas apresentarem quadros comparativos, as 9 (45\%) que o fizeram evidenciam informações objetivas e com parágrafos anexos explicando os quadros e os modelos utilizados para a avaliação. Uma informação importante que deveria constar nos quadros comparativos é o ganho ou perda com derivativos e as diferenças entre os valores de aquisição e o valor atual conforme os critérios adotados para mensuração. Destaque-se que esse item está diretamente relacionado à avaliação de derivativos a valores justos ou de mercado.

\subsection{Controle de Risco de Crédito}

O risco de crédito é a possibilidade de a empresa vir a incorrer em perdas por conta de problemas financeiros com seus clientes, ocasionando

Tabela 2 - Valores de Mercado de Ativo e Passivo

\begin{tabular}{lccccc} 
CONSOLIDADO & \multicolumn{2}{c}{2002} & & \multicolumn{2}{c}{$\mathbf{2 0 0 1}$} \\
\cline { 2 - 5 } Ativo & Contábil & Mercado & & Contábil & Mercado \\
Disponibilidades e aplicações financeiras & 369.040 & 369.040 & 153.441 & 153.441 \\
\hline Passivo & Contábil & Mercado & Contábil & Mercado \\
\hline Adiantamentos sobre contrato de câmbio & 816.138 & 804.907 & 591.391 & 593.241 \\
\hline Financ. de Matérias-primas e sobressalentes & 13.595 & 13.620 & 19.433 & 19.433 \\
\hline Securitização de recebíveis de exportação & 735.029 & 689.876 & 676.100 & 663.307 \\
\hline Outros financiamentos & 1.476 .787 & 1.265 .494 & 955.590 & 896.791 \\
\hline
\end{tabular}

Fonte: Demonstrações Contábeis do ano de 2002 da Companhia Siderúrgica Tubarão. 
a inadimplência de seus compromissos. Poucas empresas fazem a análise de risco de seus clientes (apenas 8 - 40\% - das empresas) e, em geral, apresentam justificativas para não fazê-lo, como é o exemplo da CESP.

O risco surge da possibilidade de a Companhia vir a incorrer em perdas resultantes da dificuldade de recebimento de valores faturados a seus clientes. Este risco é avaliado pela Companhia como baixo, tendo em vista o concentrado número de seus clientes, garantias contratuais e serem concessionárias para prestação de serviços públicos de distribuição de energia e não haver histórico de perdas significativas na realização de seus recebíveis.

A nota da CESP sobre gerenciamento de risco de crédito de clientes revela que não foi feito nenhum tipo de controle mais avançado pela empresa e tampouco avaliação de clientes.

A Globex Utilidades S.A. proprietária de marca Ponto Frio que, pelo mercado de varejo em que atua, deveria ter um grande controle de risco de seus clientes, apesar da pulverização, não apresenta nenhum tipo de informação relevante ao mercado sobre esse ponto.

Pela análise das vinte empresas constatouse que nenhuma delas utiliza critérios conforme os descritos na instrução 235 da CVM ou se utiliza não os divulga ao mercado. A CVM sugere, inclusive, a classificação de clientes com bases em avaliações de ratings de empresas especializadas em análise de risco. $\mathrm{Na}$ análise das demonstrações não foi verificada a presença de nenhum tipo de avaliação de risco de inadimplência de clientes e tampouco divulgado o grau de concentração das vendas.

\subsection{Controle de Risco de Taxa de Câmbio}

O risco de taxa de câmbio é a possibilidade de a companhia vir a incorrer em perdas por conta de flutuações nas taxas de câmbio, que reduzam valores nominais faturado ou aumentem valores captados no mercado. A Petróleos Ipiranga apresentou a seguinte nota sobre seu risco cambial:

A companhia celebra contratos de "swap" para troca do indexador de seus empréstimos e financiamentos em moeda estrangeira pela variação dos Certificados de Depósitos Interbancários - CDI, com instituições financeiras sediadas no País, em montantes suficientes para compensar esses eventuais impactos. Em 31 de dezembro de 2002, os ganhos das operações de "swap" no montante de $\mathrm{R} \$ 77.187$ (2001 - R\$ 146), decorrente das diferenças das variações nos indexadores contratados sobre os indexadores referenciais estão registrados em despesas financeiras. As operações com instrumentos financeiros derivativos podem assim ser demonstradas:

\section{Tabela 3 - Demonstrações de Derivativos}

\begin{tabular}{lcc}
\hline OPERAÇÕES DE SWAP & 2002 & 2001 \\
Posição ativa & & \\
\hline Variação cambial + Taxa de juros & 200.340 & 96.657 \\
\hline Posição passiva & & \\
\hline $101 \%$ do CDI & 151.066 & 102.620 \\
\hline
\end{tabular}

Fonte: Demonstrações Contábeis do ano de 2002 da Petróleos Ipiranga.

As informações da empresa contribuem pouco para a tomada de decisão do investidor, pois não apresentam a posição líquida da empresa e os resultados obtidos com derivativos até o momento.

Das empresas analisadas 15 (75\%), fazem referência a riscos de alterações no câmbio em suas atividades, mas a qualidade das informações deixa a desejar. Apesar de a Demonstração do Resultado do Exercício revelar que muitas empresas têm grande parte de suas receitas em vendas para o exterior, poucas empresas divulgam ao mercado informações sobre essas receitas em moeda estrangeira.

Por outro lado, a Telemar, de forma bastante sensata e com propriedade, apresenta a seguinte nota relativa ao tema:

Cerca de 44\% (2001 - 35\%) da dívida consolidada, excluindo pessoas ligadas, é expressa em moeda estrangeira (moeda dos Estados Unidos e cesta de moedas do BNDES). Como resultado, a Companhia está exposta a riscos cambiais que podem afetar negativamente seus negócios, situação patrimonial e financeira e resultado das operações, bem como sua capacidade de honrar as obrigações do serviço da dívida. Para reduzir a exposição da Companhia a riscos cambiais, a administração celebra contratos de "Swap"s, opções e "forwards" (contratos a termo). As operações de "swap" cambial transferem o risco de variação de moedas estrangeiras para a variação do CDI. As operações de opções cambiais são de compra e de venda de moeda dos Estados Unidos, nas quais a Companhia paga e recebe prêmios no ato da contratação. Tais prêmios são registrados em "Despesas antecipadas" e "Demais obrigações" e apropriados ao resul- 
tado de acordo com o regime de competência, pelo prazo contratual. As operações de "forwards" definem uma taxa de câmbio pré-fixada a ser adquirida quando do vencimento contratual. O valor nominal total de derivativos em moeda estrangeira ("swaps" e opções) e aplicações em moeda dos Estados Unidos em 31 de dezembro de 2002 e de 2001 eram, respectivamente, US\$ 557.891 mil e US\$ 517.000 mil (no Consolidado e na Controladora), com vencimentos de janeiro de 2003 a novembro de 2005, correspondendo a aproximadamente $26 \%$ "over" (45\% "over" na controladora) de cobertura para o risco cambial, considerando que os contratos de opções estão limitados às taxas contratadas. A taxa média de câmbio de proteção à variação cambial do dólar dos Estados Unidos dos contratos de opções é entre $R \$ 2,70$ e $R \$ 2,90$ para US\$1,00, com um prêmio médio de $2,85 \%$. A posição resumida dessas operações se apresenta como segue:

Tabela 4 - Operações com Derivativos

\begin{tabular}{|c|c|c|c|c|c|c|}
\hline \multirow[t]{2}{*}{ CONTA } & \multicolumn{2}{|c|}{$\begin{array}{l}\text { Valor dos contratos } \\
\text { de derivativos }\end{array}$} & \multicolumn{2}{|c|}{$\begin{array}{l}\text { Ganho (perda) } \\
\text { com derivativos }\end{array}$} & \multicolumn{2}{|c|}{$\begin{array}{c}\text { Ganho (perda) com } \\
\text { derivativos contabilizados }\end{array}$} \\
\hline & 2002 & 2001 & 2002 & 2001 & 2002 & 2001 \\
\hline Aplicação em moeda estrangeira & 71.412 & & 24.632 & & 24.632 & \\
\hline Swap de moeda estrangeira & 910.461 & & 84.641 & (21.278) & 84.641 & $(21.278)$ \\
\hline Opções & 989.324 & 816.781 & 22.395 & (56.181) & $(29.705)$ & (56.181) \\
\hline Termo (“forward”) & & 382.866 & 37.608 & & 37.608 & \\
\hline
\end{tabular}

Fonte: Demonstrações Contábeis do ano de 2002 da Telemar.

Como se observa acima, a nota da Telemar é clara e evidencia a real posição da empresa em relação aos riscos. É lamentável que poucas empresas tenham notas semelhantes à da Telemar.

\subsection{Controle de Risco de Preço dos Produtos}

O risco de preço de produtos é a possibilidade de a companhia vir a incorrer em perdas por conta de flutuações de preços de seus produtos, nos mercados interno e externo. Do total de empresas da amostra, apenas 6 (30\%) fizeram referência a esse tópico em suas notas explicativas.

A Light apresentou a seguinte nota a respeito de risco de mercado:

As quantidades de energia elétrica compradas pela Companhia são baseadas em estimativas do consumo de energia nos períodos subseqüentes. Parte da energia comprada esta contratada através dos denominados contratos iniciais, assinados em período anterior ao da privatização da Companhia, que fixa determinados volumes de compra até o ano de 2002, sendo reduzidos em $25 \%$ a partir de 2003 até sua extinção. A Companhia por sua opção pode efetuar compras através dos denominados contratos bilaterais, para atender eventual necessidade adicional de energia, por preços e condições negociados com a contraparte. As sobras ou faltas de energia devem ser vendidas ou compradas no mercado de energia no curto prazo e, portanto, estão sujeitas à volatilidade dos preços desse mercado que durante 2002 variaram de $R \$ 4,85$ a $R \$ 297,05$.

Já a companhia Vale do Rio Doce apresenta a seguinte nota relativa ao risco de preço:

Os preços do minério de ferro, principal produto da Companhia, são fixados através de negociações anuais entre produtores e consumidores, apresentando notável estabilidade ao longo do tempo. A Companhia não contrata operações para proteção contra variações no preço do minério de ferro. A Companhia utiliza instrumentos de "hedge" para gerenciar sua exposição às mudanças de mercado do ouro e alumínio. As operações com derivativos permitem fixar lucro médio mínimo para a produção futura. A Companhia gerencia ativamente as posições contratadas, sendo os resultados destas atividades acompanhados mensalmente, a fim de permitir que seja feitos ajustes nas metas e estratégias em resposta às condições de mercado. A tabela abaixo informa o portfólio de derivativos de ouro da Companhia em 2002 e 2001. 
Tabela 5 - Instrumentos Derivativos

\begin{tabular}{|c|c|c|c|c|c|c|c|}
\hline \multirow[t]{2}{*}{ TIPO } & \multicolumn{3}{|c|}{2002} & \multicolumn{4}{|c|}{2001} \\
\hline & Quant. (oz) & $\begin{array}{l}\text { Faixa de } \\
\text { preço } \\
\text { US\$/oz }\end{array}$ & $\begin{array}{l}\text { Ganho/perda } \\
\text { não realizado } \\
\text { em R\$ milhões }\end{array}$ & $\begin{array}{l}\text { Último } \\
\text { vecto. }\end{array}$ & Quant. (oz) & $\begin{array}{l}\text { Faixa de } \\
\text { preço } \\
\text { US\$/oz }\end{array}$ & $\begin{array}{l}\text { Ganho/perda } \\
\text { não realizado } \\
\text { em } \mathbf{R} \$ \text { milhões }\end{array}$ \\
\hline Puts compradas & 428.000 & $270-355$ & 11 & Dez/07 & 422.000 & $270-340$ & 25 \\
\hline Calls vendidas & 595.000 & $316-407$ & (63) & Dez/07 & 718.000 & $308-366$ & (8) \\
\hline Instrumentos Híbridos & 20.000 & - & (1) & Nov/06 & 25.000 & - & - \\
\hline Total & & & (53) & & & & 17 \\
\hline
\end{tabular}

Fonte: Demonstrações Contábeis do ano de 2002 da Companhia Vale do Rio Doce.

Como se observa pelos exemplos acima, na proteção contra riscos de mercado a nota da Vale do Rio Doce é bem mais completa e realizada com acurácia do que a da Light. Assim, a analise qualitativa comparativa é importante para se determinar a aderência às normas exigidas pelos órgãos reguladores e pelo mercado.

\section{CONSIDERAÇOES FINAIS}

A análise das Demonstrações Contábeis das vinte maiores empresas brasileiras, no que se refere à evidenciação de instrumentos financeiros derivativos, revela que a grande maioria das companhias abertas, ainda, não informam, de acordo com a Instrução Normativa 235 da CVM, corretamente e de forma clara, o mercado de suas operações com derivativos.

Desde que a matéria foi disciplinada pela CVM em 1995, ainda há diferenças entre as práticas de divulgação de instrumentos financeiros pelas companhias abertas brasileiras e as determinações da Instrução Normativa 235/95. Essas diferenças podem ser, assim, resumidas, conforme entendimento da própria CVM e constatações no decorrer deste trabalho:
- não divulgação das políticas de atuação sobre os riscos a que estão sujeitos os instrumentos financeiros e derivativos, os tipos de riscos envolvidos (riscos de mercado, taxa de câmbio e de crédito) e o controle das operações no mercado de derivativos;

- imprecisões na divulgação da nota, faltando não só a comparação entre o valor contábil e o valor de mercado, como também informações sobre os critérios de avaliação adotados para determinação desse valor de mercado;

- informação da inexistência de instrumentos financeiros, enquanto o balanço patrimonial revelava o contrário;

- informação de que o valor contábil é o mesmo (ou próximo ao) valor de mercado, provavelmente por não terem efetuado qualquer cálculo nesse sentido.

Pela análise quantitativa das empresas, chegou-se à seguinte conclusão em termos de evidenciação das vinte empresas analisadas, demonstradas na Tabela 6:

Tabela 6 - Evidenciação de Derivativos - em \%

\begin{tabular}{|c|c|c|c|c|c|c|c|}
\hline \multirow[b]{2}{*}{ Itens - Empresas } & \multirow[b]{2}{*}{$\begin{array}{l}\text { Nota } \\
\text { Explicativa }\end{array}$} & \multirow[b]{2}{*}{$\begin{array}{l}\text { Objetivos, } \\
\text { Finalidades } \\
\text { e Intenções }\end{array}$} & \multirow[b]{2}{*}{$\begin{array}{l}\text { Premissas } \\
\text { de Avaliação }\end{array}$} & \multirow[b]{2}{*}{ Quadros } & \multicolumn{3}{|c|}{ Controle de Risco } \\
\hline & & & & & Crédito & $\begin{array}{l}\text { Taxa de } \\
\text { Câmbio }\end{array}$ & $\begin{array}{l}\text { Preço dos } \\
\text { Produtos }\end{array}$ \\
\hline Apresentam & 100 & 60 & 25 & 45 & 40 & 75 & 30 \\
\hline Não apresentam & 0 & 40 & 75 & 55 & 60 & 25 & 70 \\
\hline
\end{tabular}

Fonte: Elaborado pelos autores com base no resultado da pesquisa. 
Apesar de os instrumentos financeiros derivativos prestarem-se, principalmente, a estratégias de gestão de risco, muitas vezes eles são utilizados para especulação e operações financeiras de curto prazo. Assim, invariavelmente, os instrumentos financeiros sujeitam a empresa a outros fatores de risco para os quais ela não estava originariamente exposta. Essas informações, obrigatoriamente, deveriam estar presentes nas notas explicativas elaboradas pelas companhias abertas.

A nota explicativa para instrumentos financeiros deve conter, de modo integrado, uma descrição qualitativa dos fatores de risco de mercado que afetam os negócios de uma companhia aberta (risco de preços de suas mercadorias, risco de taxa de juros, risco de taxa de câmbio, risco de crédito, risco inflacionário, risco de liquidez etc.) e, como a informação mais relevante, a estratégia adotada pela admi- nistração da companhia para gestão desses riscos, e em que contexto estão inseridos os instrumentos financeiros. Tais informações não foram prestadas pela maioria das empresas analisadas.

Outro ponto que deve ser tratado diz respeito a procedimentos contábeis. Devem ser divulgadas informações no que respeita à política contábil dispensada ao instrumento financeiro (critério de mensuração, classificação contábil recebida, registro dos efeitos patrimoniais, entre outros), de modo que os usuários da informação tenham todos os elementos necessários às suas análises.

Ainda assim, a despeito da enorme quantidade de desvios e incorreções encontrados nas Demonstrações Contábeis analisadas, todas de grandes e tradicionais empresas brasileiras, saliente-se, por fim, que em nenhuma delas o parecer dos auditores independentes fez qualquer referência ao fato.

\section{REFERÊNCIAS BIBLIOGRÁFICAS}

BENSTON, G.; MIAN, S.. Financial reporting of derivatives: an analysis of the issues, ev aluations proposals, and a suggested solution. The Journal of Financial Engineering, 4, 1997, 217-246.

BRASIL. Lei 6404 de 1976. Dispõe sobre as Sociedades por Ações.

BLANKLEY, Alan; REINHOLD, Lamb; SCHOROEDER, Richard. Compliance with SEC disclosure requirements about market risk. Journal of Derivatives, v. 7, issue 3, Spring 2000.

COMISSÃO DE VALORES MOBILIÁRIOS. Instrução Normativa 235 de 23 de março de 1995. Dispõe sobre a divulgação, em nota explicativa, do valor de mercado dos instrumentos financeiros, reconhecidos ou não nas demonstrações financeiras das companhias abertas e dá outras providências.

GAO: General Accounting Office, Special Report to US Congress on Financial Instruments and Capital Markets, 1998. p. 18.

GUAY, Wayne. R. The impact of derivatives on firm risk: an empirical examination of new dervivative users. Journal of Accounting and Economics, 26, p. 319-351. 1999.
ISHIKAWA, Junji. A social science of contemporary value-based accounting: economic foundations of accounting for financial instruments. Critical Perspectives on Accounting. 2003.

LAKATOS, Eva Maria; MARCONI, Marina de Andrade. Metodologia do trabalho científico. 4. ed. São Paulo: Atlas, 1992, p. 82.

LOPES, Alexsandro Broedel. A informação contábil e o mercado de capitais. São Paulo: Thomson, 2002.

CARVALHO, Luiz Nelson G.. Contabilização de operações com derivativos: uma comparação entre o SFAS 133 e o arcabouço emanado pelo COSIF. Caderno de estudos, São Paulo, FIPECAFI, n. 20, jan/abr., 1999.

SEOW, Gim S.; TAM, Kinsun. The usefulness of derivative-related Accounting Disclosures. Review of Quantitative Finance and Accounting, 19, 2002, p. 273-291.

Statement of Financial Accounting Standars - SFAS 133 - Accounting for derivatives instruments and Hedging activies - Junho/1998.

BIBLIOGRAFIA COMPLEMENTAR

ASSAF NETO, Alexandre. Mercado financeiro. 2. ed. São Paulo: Atlas, 1999

ARONOVICH, Selmo; PEREIRA, Thiago Rabelo. Derivativos de crédito: uma introdução ao instrumento financeiro e potenciais usos. Revista do BNDES, v. 10, n. 20, 2003, p. 155-172.

BENSON, G. J.. Accounting for derivatives: back to basics. Journal of Applied Corporate Finance, v. 10, n. 3, 1997, 46-58.
BREALEY, Richard A.; MYERS, Stewart C.. Fundamentos de administração financeira. Rio de Janeiro: McGraw-Hill, 2003.

COSTA JR., Jorge Vieira da. Uma avaliação do nível de evidenciação das companhias abertas, no Brasil, no tocante a instrumentos derivativos. Revista Contabilidade \& Finanças - USP, São Paulo, n. 32, p. 23-39, maio/agosto, 2003. 
HULL, John. Introdução aos mercados futuros e de opções. 2 ed, Bolsa de Mercadoria e Futuros: São Paulo, 2000.

IUDíCIBUS, S. de; MARTINS, E.; GELBECKE, E.R.. Manual de contabilidade. 6. ed. São Paulo: Atlas, 2003.

LOPES, Alexsandro Broedel. LIMA, Iran Siqueira. Perspectivas para a pesquisa em contabilidade: 0 impacto dos derivativos. Revista Contabilidade \& Finanças FIPECAFI - FEA - USP, São Paulo, FIPECAFI, v. 15, n. 26, p. 25-41, maio/agosto 2001.

Contabilidade e controle de operações com derivativos São Paulo: Pioneira, 1999.

MASHEANE, Motseoa. Derivatives: accounting and economic issues. Journal of Accounting Education, v. 16, ns. 3/4, p. 591-598, 1998.

SILVA NETO, Lauro de Araújo. Opções do tradicional ao exótico. 2. ed., São Paulo: Atlas, 1996.
Derivativos: definições, emprego e risco. 2. ed., São Paulo: Atlas, 1998.

ROSS, Stephen A. et al. Administração financeira. São Paulo: Atlas, 1995.

HWANG, Angela L. J.. Comparative analysis of accounting treatments for derivatives. Journal of Accounting Education, 20, 2002, p. 205-233.

SOARES, Jairo da Rocha. A Nova Feição à Contabilidade de Instrumentos Financeiros: Aplicações do IASC e US GAAP. ENANPAD. 2000.

SANVICENTE \& MELLAGI FILHO. Mercado de capitais e estratégias de investimento. São Paulo: Atlas, 1996.

Nota:

Endereço dos autores:

Universidade Federal de Santa Catarina

Centro Sócio-Econômico

Campus Universitário - Trindade

Florianópolis - SC

88040-900

R. Cont. Fin. - USP, São Paulo, n. 39, p. 68 - 80, Set./Dez. 2005 